\title{
Evaluation of the response of lisdexamfetamine in children and adolescents with ADHD: quasi-experimental study
}

\author{
Barragán Pérez Eduardo,' García Beristain Juan Carlos,' Hidalgo Gutiérrez Ricardo'
}

Departamento de Neurología, Hospital Infantil de México Federico Gómez, Ciudad de México, México.

\section{Correspondence:}

Juan Carlos García Beristain

Departamento de Neurología, Hospital Infantil de México Federico Gómez.

Dr. Márquez 162 Col. Doctores, Del. Cuauhtémoc, Ciudad de México, México.

Phone: +52 555588 - 9392

Email: beristainjc@gmail.com

Received: 19 July 2018

Accepted: 4 December 2018

\section{Citation:}

Barragán Pérez, E., García Beristain, J. C., Hidalgo Gutiérrez, R. (2018). Evaluation of the response of lisdexamfetamine in children and adolescents with ADHD: quasi-experimental study. Salud Mental, $41(6), \quad 279-285$. doi: 10.17711/SM.0185-3325.2018.040

\section{(c) (7) (을}

\begin{abstract}
Introduction. Attention deficit hyperactivity disorder (ADHD) is one of the most common neurodevelopmental disorders. Although lisdexamfetamine dimesylate (LDX) offers a treatment alternative, clinical evidence of LDX for ADHD has not been explored in Latin American pediatric population. Objective. To evaluate the LDX response in Mexican pediatric patients with ADHD. Method. We designed a quasi-experimental, uncontrolled before and after study to evaluate the LDX response in patients with severe ADHD. We established a diagnosis of ADHD according to DSM-5 criteria. We formed three groups: without previous treatment (group A), in treatment with stimulant drugs (group B) or in treatment with non-stimulant drugs (group C). Prior to the start of the study, letters of consent and informed consent were signed. We evaluated the effect of LDX based on the difference between ADHD-RS scores at the beginning and after six months. Results. We recruited a total of 144 patients (group A: 48 patients, group B: 57 patients, group C: 39 patients). All the groups showed a significant decrease in the mean score of ADHD-RS (Attention Deficit Hyperactivity Disorder Rating Scale) at six months (group A 37.57 vs. 22.34, $p<.01$ ), (group B 36.72 vs. 24.45; $p<.01$ ), (group C 38.54 vs. $24.3, p<.01$ ). Fewer than $30 \%$ of the subjects showed a significant adverse reaction, the most frequent ones being: sleep disturbance (primary insomnia) $24 \%$ and decreased appetite in $20 \%$. Discussion and conclusion. Treatment with LDX is an effective, well-tolerated pharmacological option for Mexican pediatric patients with ADHD.
\end{abstract}

Keywords: ADHD, lisdexamfetamine dimesylate, attention deficit, motor hyperactivity.

\section{RESUMEN}

Introducción. El trastorno por déficit de atención con hiperactividad (TDAH) es uno de los trastornos del neurodesarrollo más comunes. Aunque el dimesilato de lisdexanfetamina (LDX) ofrece una alternativa de tratamiento, la evidencia clínica de LDX para TDAH no se ha explorado en población pediátrica latinoamericana. Objetivo. Evaluar la respuesta de LDX en pacientes pediátricos mexicanos con TDAH. Método. Diseñamos un estudio cuasiexperimental no controlado de antes y después para evaluar la respuesta de LDX en pacientes con TDAH grave. Establecimos el diagnóstico de TDAH de acuerdo con criterios del DSM-5. Conformamos tres grupos: sin tratamiento previo (grupo A), en tratamiento con fármacos estimulantes (grupo B) o en tratamiento con fármacos no estimulantes (grupo C). Previo al inicio del estudio se firmaron las cartas de consentimiento y asentimiento informado. Evaluamos el efecto de LDX con base en la diferencia de los puntajes de ADHD-RS al inicio y posterior a seis meses. Resultados. Reclutamos un total de 144 pacientes (grupo A: 48 pacientes, grupo B: 57 pacientes, grupo C: 39 pacientes). Todos los grupos mostraron una disminución significativa en la media de puntaje de ADHD-RS (Attention Deficit Hyperactivity Disorder Rating Scale) a los seis meses (grupo A 37.57 vs. $22.34 ; p<.01$ ), (grupo B 36.72 vs. $24.45 ; p<.01$ ), (grupo C 38.54 vs. $24.3 ; p<.01)$. Menos del $30 \%$ de los sujetos presentó alguna reacción adversa importante, siendo las más frecuentes: alteraciones del sueño (insomnio primario) 24\% y disminución del apetito en $20 \%$. Discusión y conclusión. El tratamiento con LDX es una opción farmacológica efectiva y bien tolerada para pacientes pediátricos mexicanos con TDAH.

Palabras clave: TDAH, dimesilato de lisdexanfetamina, déficit de atención, hiperactividad motora. 


\section{INTRODUCTION}

Attention deficit hyperactivity disorder (ADHD) is a disorder that manifests in childhood with symptoms such as hyperactivity, impulsivity, and/or lack of attention. These symptoms affect cognitive, academic, behavioral, emotional, and social functioning (Lopez, 2014). ADHD is considered one of the most common neurodevelopmental disorders, with an estimated global prevalence of approximately $5 \%$ at school age (Polanczyk, de Lima, Horta, Biederman, \& Rohde, 2007; Polanczyk, Willcutt, Salum, Kieling, \& Rohde, 2014). The recommended treatment for ADHD is multimodal, including pharmacological and non-pharmacological interventions. Medications for ADHD include psychostimulants (derivatives of methylphenidate and amphetamines) and non-psychostimulant drugs (atomoxetine and guanfacine) (American Academy of Pediatrics, 2011; National Institute for Health and Care Excellence, 2018).

Lisdexamfetamine dimesylate (LDX) is an ADHD drug which has attracted the largest volume of research in recent years. It provides a treatment alternative, with a low abuse potential and a tolerability profile similar to that of other stimulant drugs (Diaz-Orueta, Fernandez-Fernandez, Morillo-Rojas, \& Climent, 2016). The duration of the action of LDX is longer than that reported for any other long-acting stimulant medication, extending to at least 13 and 14 hours post-dose in children and adults with ADHD, respectively (Ermer, Pennick, \& Frick, 2016). LDX was approved by the Food and Drug Administration (FDA) in February 2007 for ADHD treatment in children ages six to 18. In Mexico, it was authorized by the Federal Commission for Protection against Health Risks in May 16, 2014 for use in children, adolescents, and adults with ADHD, becoming commercially available in May 2016 (COFEPRIS, 2015).

From the first studies to the most recent reviews, LDX has been shown to be more effective than a placebo in reducing the main ADHD symptoms (Biederman, Krishnan, Zhang, McGough, \& Findling, 2007; Faraone \& Buitelaar, 2010; Punja, Schmid, et al., 2016; Punja, Shamseer, et al., 2016; Stuhec, Munda, Svab, \& Locatelli, 2015). A meta-analysis reported that amphetamines are moderately more effective than methylphenidate for ADHD treatment (Coghill et al., 2013; Faraone \& Buitelaar, 2010; Hodgkins et al., 2012). The safety and tolerability profile of LDX in ADHD patients is similar to that of other stimulants (Coghill, Caballero, Sorooshian, \& Civil, 2014).

In most of the studies where the adverse effects due to LDX use were evaluated, loss of appetite was the most common. In up to $25 \%$ of patients treated with LDX, regardless of age, weight loss occurs in $9 \%$ of children and adolescents, anorexia in $10.8 \%$ of patients, and insomnia is common in all age groups occurring in up to $11 \%-19 \%$ of patients treated with LDX. Headaches occur in just over $10 \%$ of patients receiving LDX and dry mouth occurs in
$7 \%$ of children and adolescents (Biederman et al., 2007; Coghill et al., 2014; Findling et al., 2011; 2013).

Genetic variants affect the response to drugs, altering their pharmacokinetics and pharmacodynamics, thus modifying the profile of effectiveness and safety in the Latin American population (Gonzalez-Covarrubias et al., 2016; Sosa-Macías et al., 2016). However, on the basis of available data, since there are as yet no studies on LDX documenting its use in a child and adolescent population in our region, we decided to evaluate its effectiveness, tolerability and safety in the Mexican pediatric population with ADHD treated at our institution.

\section{METHOD}

\section{Type of Study}

Before and after longitudinal, prospective, quasi-experimental study.

\section{Location}

Pediatric Neurology Outpatient service at the Hospital Infantil de México Federico Gómez, between June 2016 and February 2017.

\section{Population}

We included patients of both sexes, aged between six and 16, with an ADHD diagnosis according to DSM-5 criteria. We excluded patients with any neurological disease (epilepsy, brain damage, cognitive dysfunction, and autism spectrum disorder), known hypersensitivity to LDX components or those who had previously received LDX treatment, as well as accentuated comorbidities in their clinical records known to be contraindications for LDX use.

\section{Procedures}

We formed three treatment groups. The first group (A), comprised patients without previous pharmacological treatment (naive); the second group (B), those with previous treatment with methylphenidate (MTF) (any of its presentations), and the last group (C), those with previous treatment with any other non-stimulant medication such as atomoxetine or antiepileptic drugs. Prior to the start of the study, letters of consent and informed consent were signed in all cases.

In all three groups, we performed evaluations in the outpatient department of the neurology department. Patients in the naive group had to have been diagnosed with ADHD according to the DSM-5 criteria for any subtype or presentation and to have an ADHD-RS score of over 36 
points to qualify for the study (Goodman et al., 2010). In the other two groups, candidates were eligible for the study if they still persisted with a diagnosis of ADHD (validated with the DSM-5 criteria as non-remission or remitted), and had scores equal to or above 36 on the ADHD-RS despite being under treatment with some of the previously established medications (MTF, ATM, or others) for more than six weeks at appropriate doses (MTF in any presentation at a dose higher than $.8 \mathrm{mg} / \mathrm{kg} /$ day, ATM $1 \mathrm{mg} / \mathrm{kg} /$ day and the corresponding doses of the other medicines) without having experienced an improvement in the symptoms evaluated by ADHD-RS or having been forced to suspend treatment due to side effects.

Clinical evaluations were carried out in four visits: at the outset, and at one, three, and six months. In each visit, a medical evaluation was undertaken including weight, height, pulse, blood pressure, cephalic perimeter, complete neurological evaluation, and time of sleep onset (modification or not of bedtime), as well as an evaluation of the response to treatment with the global clinical impression scale of the severity of symptoms and functional deterioration (GCI), and the ADHD-RS instrument. The GCI scale is a clinical description describing the severity of the patient's symptoms in relation to the total clinical experience of patients with ADHD. The GCI consists of two subscales which respectively assess the severity of symptoms and the improvement of symptoms because of therapeutic interventions. It rates severity from one (normal, not sick) to seven (most extremely sick patients) and improvement from one (much better) to seven (much worse) applied to the parents of the patients. The ADHD-RS instrument comprises 18 items in the A criterion for a diagnosis of ADHD indicated in the DSM-5. The attention deficit and hyperactivity/impulsivity dimensions comprise nine items each. Each item is valued from zero to three points, with a minimum score of zero and a maximum of 54 . This scale has been designed and validated to be completed by a parent of the evaluated patient.

Once the parents had been informed about the study and follow-up, they signed the consent form and the patients signed the informed consent form and were assigned to begin using LDX. All the parents were trained to administer the medication, taught to look for the effectiveness response and side effects (a list was provided of the latter), and shown the methods to administer the medication appropriately in case the dose to be administered was not the same as the available commercial presentations of LDX $(30,50$, and $70 \mathrm{mg})$. In this case, as specified by the manufacturer, the contents of the $30 \mathrm{mg}$ capsule were diluted in water or juice and inserted into a $10 \mathrm{ml}$ syringe with a conversion to $\mathrm{ml}$ in order to administer the initial dose established at $5 \mathrm{ml}$ per day. After completing the $30 \mathrm{mg}$ dose in schoolchildren or $50 \mathrm{mg}$ in adolescents, the closed capsule treatment was continued.
Initially the dose was $15 \mathrm{mg} /$ day in a single morning dose and gradual adjustments were made every week via telephone, raising the previous dose by $5 \mathrm{mg}$ during the first four weeks (5 mg each week) until the suggested dose of $30 \mathrm{mg} /$ day in schoolchildren and $50 \mathrm{mg} /$ day in adolescents (over 12 years) was reached, following international recommendations (American Academy of Pediatrics, 2011; BoleaAlamañac et al., 2014; CADDRA, 2011; National Institute for Health and Care Excellence, 2018). Adjustments were made in the first four weeks by asking parents whether there had been an improvement in symptoms and tolerance, and whether any adverse effects (AE) had been observed. AEs were evaluated in the same way as any clinical event mentioned by parents and with an impact on patients, regardless of whether they were associated with the medication, including the exacerbation of pre-existing ADHD symptoms. Evaluation was carried out through questions concerning the most frequent adverse effects. If an $\mathrm{AE}$ occurred, the dose was reduced to $10 \mathrm{mg} /$ day if it occurred at the start of treatment or $5 \mathrm{mg}$ reductions were made to treatment if the $\mathrm{AE}$ coincided with the recent increase in the dose, and if it persisted, treatment was discontinued and the patient was recorded as an attempt at treatment.

\section{Measures}

In clinical evaluations, we used GCI and ADHD-RS to measure the level of reduction of symptoms. We considered that there was a response to treatment if patients had a one point decrease in monthly GCI or if there was subsequently a reduction of over five points in the ADHD-RS, with respect to the initial or prior evaluation.

\section{Statistical analysis}

We obtained descriptive statistics with measures of central tendency and dispersion for the description of clinical and demographic characteristics. The difference in averages was analyzed through a mixed ANOVA test to evaluate the distribution of variables according to their normality.

A $p<.05$ value was considered a statistically significant difference.

\section{RESULTS}

We recruited a total of 144 patients who met the inclusion criteria. We included 106 schoolchildren and 38 adolescents by age group (Table 1 ). In group A, we had 48 patients $(33.3 \%), 26$ of whom (54\%) were male. The form of presentation of ADHD was distributed as follows: $58 \%$ combined, $29 \%$ inattentive, and $13 \%$ hyperactive. In group B, we had 57 patients $(39.5 \%), 41$ of whom $(72 \%)$ were male. The form of presentation of ADHD was distributed as follows: 


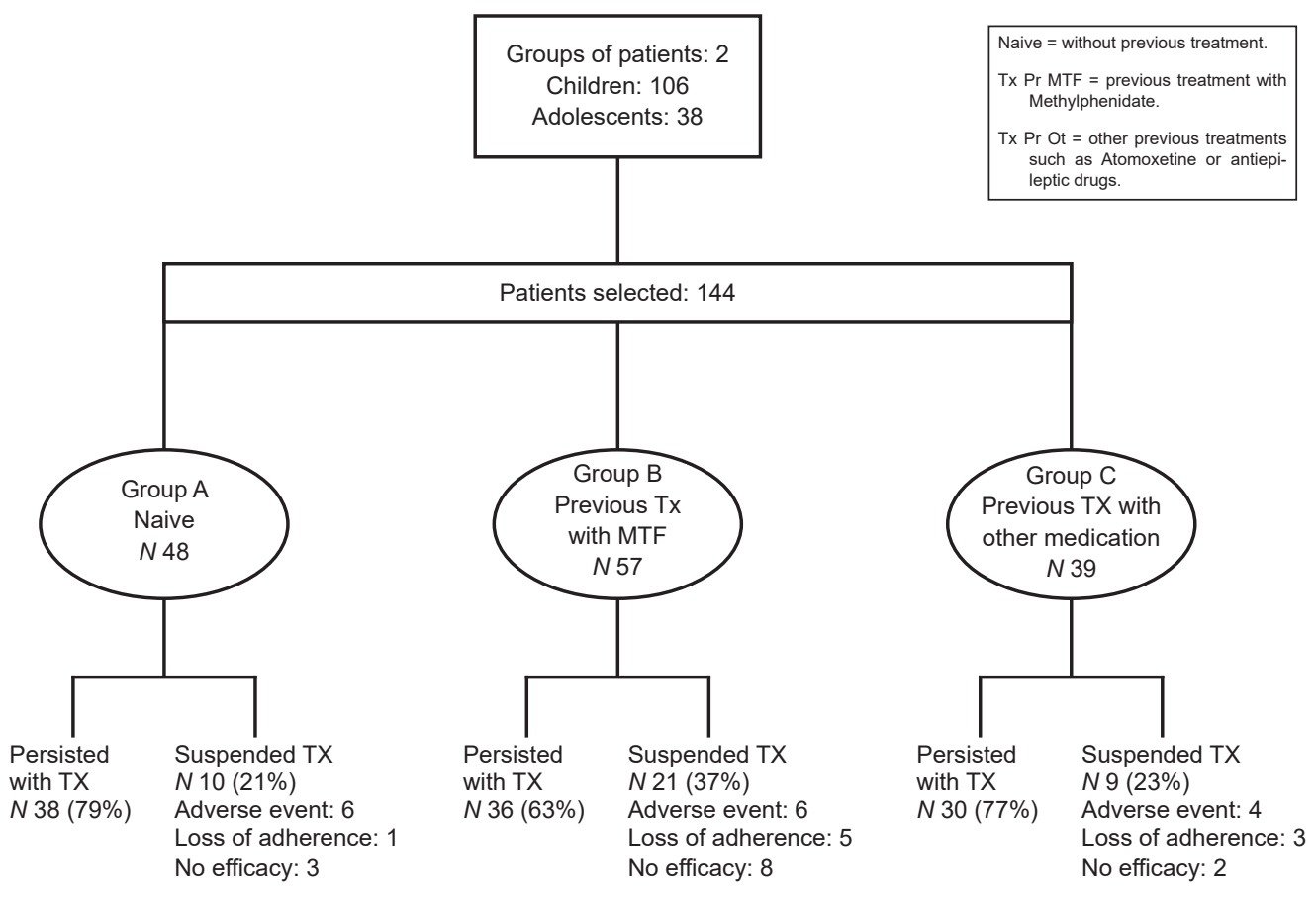

Figure 1. Flowchart of study showing composition of study groups, as well as results after follow-up in each group.

$63 \%$ combined, $30 \%$ inattentive, and $7 \%$ hyperactive. In group C, we had 39 patients (27\%), 25 of whom (64\%) were male. The form of presentation of ADHD was distributed as follows: $54 \%$ combined, $41 \%$ inattentive, and $5 \%$ hyperactive. The final results of the groups are shown in Figure 1.

Based on the ADHD-RS scale for parents, we observed a significant improvement in all groups from the first month of treatment and throughout the study period. Group A or treatment-naive patients showed significant improvement $(p<.003$ CI $95 \%$ [17.7 - 38.6]), as did group B or those pre-

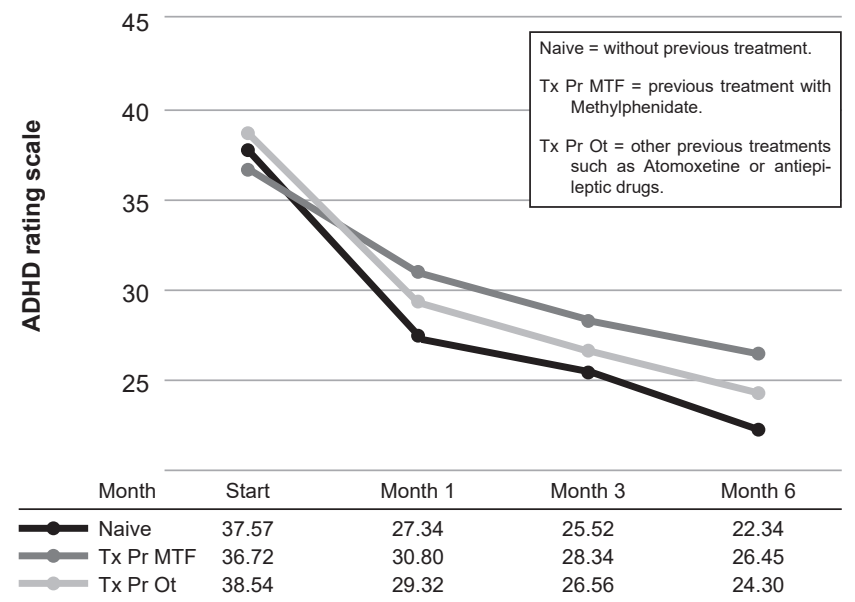

Figure 2. Graph showing the evolution of patients by study group according to the ADHD rating scale. viously treated with MTF $(p<.001$ CI 95\% [23.4 - 37.68]) and the group previously treated with non-stimulants and other forms of medication ( $p<.002$ CI 95\% [19.7 - 39.63]). The details and changes in the scores for the three groups in the various evaluations are given in Figure 2.

Qualitatively speaking and based on the general clinical impression scale (GCI), there was a marked improvement in all groups of patients at the end of the study; details are shown in Figure 3.

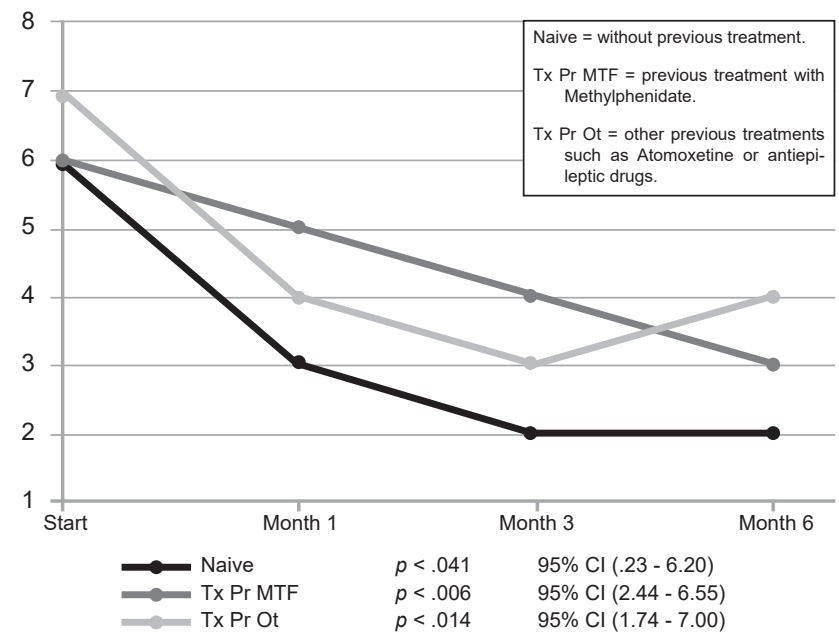

Figure 3. Graph showing evolution of different groups through the Global Clinical Impression Scale (GCl) from month 1 to 6 . 
A total of 85 patients reported $\mathrm{AE}$ at the beginning of treatment, associated with the initial dose ( $>15 \mathrm{mg} /$ day $)$, decreasing to 59 patients when the dose was reduced $(<$ $15 \mathrm{mg}$ /day). Adverse effects were significant in $12 \%$ of the patients in group A, $10 \%$ in group B, and $10 \%$ in group $\mathrm{C}$, which warranted the suspension of treatment. The most common adverse effects can be seen in Table 1 .

In most patients, it was observed that the best tolerated initial dose in children and adolescents was $10 \mathrm{mg} /$ day. The average final dose considered effective for the entire group was $30 \mathrm{mg} / \mathrm{day}$, regardless of the age and weight of the patient. After two months of treatment, in $40 \%$ of the adolescents it was necessary to adjust the dose to $50 \mathrm{mg} /$ day, producing a very favorable response.

\section{DISCUSSION AND CONCLUSION}

ADHD is the most frequent neuropsychiatric condition observed in children and adolescents and so it is a common cause of consultation (Pérez, 2010). This causes repercussions in all areas of patients' lives and requires a multimodal treatment in which the cornerstone is pharmacological treatment. In Mexico, several types of medication are available for the management of these patients, the most commonly used forms of medication being MTF in its different presentations, as well as ATM. However, despite their enormous effectiveness, there are many of patients who do not respond to them or who may not tolerate them (which may amount to $30 \%$ of patients, depending on the first treatment begun) (Barragán-Pérez et al., 2007).

In 2009, the multimodal treatment algorithm for Latin American schoolchildren recommended that basic psychoeducation be provided after the first treatment strategy; and that pharmacological management should begin at stage 1. Within the drugs recommended, the use of stimulants, whether MTF or amphetamine, was established as the first line of treatment (de la Peña Olvera et al., 2009). According to Canadian guidelines, CADDRA and LDX, together with other stimulants, is the medicine that has been considered as the first-line management for school children and adolescents with ADHD since 2014 (CADDRA, 2011). LDX has proven to have a similar profile of efficacy and safety, and in some publications it is shown to be superior to that of MTF (Li, Gao, He, Zhang, \& Wang, 2017; Punja, Shamseer, et al., 2016). Nevertheless, it is essential to be able to evaluate the clinical behavior of the idiosyncratic response of Mexican patients, since we know that each ethnic group, race or region may have different responses to therapeutic interventions (Barragán, Breuer, \& Döpfner, 2017), particularly since LDX does not have a weighting per $\mathrm{mg} / \mathrm{kg} /$ day but only per $\mathrm{mg} /$ day. The internationally recommended LDX dose is $30 \mathrm{mg} / \mathrm{day}$, the goal being to reach an average dose between 30 and $50 \mathrm{mg}$ /day (Boellner, Stark, Krishnan,
Table 1

Table showing the most frequent adverse effects during the study during the first ( $>15 \mathrm{mg} /$ day) and second study period (<15mg/day)

\begin{tabular}{lcc}
\hline & \multicolumn{2}{c}{ LDX } \\
\cline { 2 - 3 } & $\begin{array}{c}\text { (First period) } \\
>15 \mathrm{mg} / \mathrm{day}\end{array}$ & $\begin{array}{c}\text { (Second period) } \\
<15 \mathrm{mg} / \mathrm{day}\end{array}$ \\
Adverse events & $N=85(\%)$ & $N=59(\%)$ \\
\hline Any & $58(68 \%)$ & $21(35.5 \%)$ \\
Decreased appetite & $19(22 \%)$ & $5(8.47 \%)$ \\
Headache & $16(18.8 \%)$ & $4(6.77 \%)$ \\
Insomnia & $24(28.8 \%)$ & $11(18.6 \%)$ \\
Weight loss & $12(14.1 \%)$ & $3(5.08 \%)$ \\
Nausea & $7(8.2 \%)$ & $3(5.08 \%)$ \\
Anorexia & $17(20 \%)$ & $8(13.8 \%)$ \\
Epigastric pain & $6(7.2 \%)$ & $3(5.08 \%)$ \\
Abdominal pain & $5(5.8 \%)$ & $2(3.3 \%)$ \\
Initial insomnia & $17(20 \%)$ & $7(11.86 \%)$ \\
\hline
\end{tabular}

Note: LDX Lisdexamfetamine Dimesilate.

\& Zhang, 2010). However, as a precaution for evaluating the susceptibility of Mexican patients, we decided to begin with a dose of $15 \mathrm{mg} /$ day.

The three groups of patients evaluated are similar about age and gender, which facilitates the obtainment of a better evaluation of patients' responses. The most frequent type of ADHD is still the combined one, with a predominance of the male sex as reported in other studies (Faraone, Sergeant, Gillberg, \& Biederman, 2003). It is important to note that within the patients stopped treatment, the three groups are within the frequency for any other group of treatments, which suggests that there is no increase in suspensions with LDX due to any specific effect of the drug (Riera et al., 2017).

Suspensions due to lack of response were more frequent in group 2 than in the other two groups, where suspension because of side effects was more frequent. This was thought to be due to the fact the group previously exposed to stimulants such as MTF had more experience with stimulant use, and that in treatment-naive patients and those with other non-stimulant treatments, it is easier to observe the power of stimulants, which encourages the quicker and more timely perception observed in the GCI of this group of patients. Likewise, since the perception of side effects is more evident in this group of patients, we believe it can be an excellent strategy as a first treatment option or as a second drug after a non-stimulant and that it can reinforce the measures of perception when it is given after a stimulant, particularly one with sustained action such as MTF. Within the three main symptoms of ADHD, and following the results within the decrease in ADHD-RS scores in the various items that measure inattention, hyperactivity, and impulsivity, as well as the DSM-5 symptoms, impulsivity is the one that responds best and most quickly to LDX doses, which is why we consider it an excellent strategy for patients with impulsivity. 
At the same time, it is observed that side effects are very like those of stimulants (Coghill et al., 2014), the most common ones being initial insomnia, loss of appetite, and headaches, as can be seen in Table 1. When the initial dose of $15 \mathrm{mg}$ /day was adjusted to $10 \mathrm{mg} /$ day, there was a significant decrease in the frequency and intensity of side effects, which fell from $85 \%$ to $59 \%$. An initial dose of $10 \mathrm{mg} /$ day is therefore suggested to reduce the likelihood of immediate side effects and adjust the dose by increments of $5 \mathrm{mg} /$ day/ week.

The internationally recommended dose is the same effective dose observed in our patients, which encourages better adherence and tolerance due to the low dose, with adequate performance. This probably contributed to the fact that on average, most patients $(>70 \%)$ adhered to treatment for six months, which is an excellent adherence to an ADHD medication (Wang et al., 2016). The results obtained in this study indicate that treatment with LDX has a significant response in patients with ADHD who have not received treatment, or who have had previous stimulant or non-stimulant treatment, with the adverse effects related to treatment being very similar to those of other stimulant drugs according to international literature.

The behavior of this stimulant drug in this group of Mexican pediatric patients is very similar to that of groups analyzed internationally regarding the expected response. The perception of improvement by parents is significant in all the groups of patients analyzed, which could encourage better adherence to treatment. We can therefore conclude that today, LDX is an alternative with a good response in the treatment of patients with ADHD in any of its presentations. Its adverse effects are very similar to those of other drugs included in the category of stimulants. Likewise, it is important to begin with suggested low doses at a rate of $10 \mathrm{mg} / \mathrm{kg}$ with weekly increments of $5 \mathrm{mg} / \mathrm{kg}$ to reach the recommended doses of a $30 \mathrm{mg}$ capsule in child patients or $50 \mathrm{mg}$ in adolescent patients in order to avoid dividing up capsule contents or else to maintain treatment in keeping with the dose response in order to prevent the presence of adverse events as far as possible. It will be necessary to follow up various population groups under this treatment, to determine the long-term response and the frequency of adverse effects.

\section{Funding}

None.

\section{Conflict of interest}

The lead author participates as a speaker in events related to the drug manufacturer.

\section{Ethical considerations}

This study was conducted with the recognition and approval of the Ethics and Research Committee of the Hospital Infantil de México.

\section{REFERENCES}

American Academy of Pediatrics. (2011). ADHD: Clinical Practice Guideline for the Diagnosis, Evaluation, and Treatment of Attention-Deficit/Hyperactivity Disorder in Children and Adolescents. Pediatrics, 128(5), 1007-1022. doi: 10.1542/ peds.2011-2654

Barragán-Pérez, E., de la Peña-Olvera, F., Ortiz-León, S., Ruiz-García, M., Hernández-Aguilar, J., Palacios-Cruz, L., \& Suárez-Reynaga, A. (2007). Primer consenso latinoamericano de trastorno por déficit de atención e hiperactividad. Boletín médico del hospital infantil de México, 64(5), 326-343.

Barragán, E., Breuer, D., \& Döpfner, M. (2017). Efficacy and Safety of Omega-3/6 Fatty Acids, Methylphenidate, and a Combined Treatment in Children with ADHD. Journal of Attention Disorders, 21(5), 433-441. doi: $10.1177 / 1087054713518239$

Biederman, J., Krishnan, S., Zhang, Y., McGough, J. J., \& Findling, R. L. (2007). Efficacy and tolerability of lisdexamfetamine dimesylate (NRP-104) in children with attention-deficit/hyperactivity disorder: A Phase III, multicenter, randomized, double-blind, forced-dose, parallel-group study. Clinical Therapeutics, 29(3), 450-463. doi: 10.1016/S0149-2918(07)80083-X

Boellner, S. W., Stark, J. G., Krishnan, S., \& Zhang, Y. (2010). Pharmacokinetics of lisdexamfetamine dimesylate and its active metabolite, d-amphetamine, with increasing oral doses of lisdexamfetamine dimesylate in children with attention-deficit/hyperactivity disorder: A single-dose, randomized, open-label, crossover. Clinical Therapeutics, 32(2), 252-264. doi: 10.1016/j.clinthera.2010.02.011

Bolea-Alamañac, B., Nutt, D. J., Adamou, M., Asherson, P., Bazire, S., Coghill, D., ... \& Young, S. J. (2014). Evidence-based guidelines for the pharmacological management of attention deficit hyperactivity disorder: Update on recommendations from the British Association for Psychopharmacology. Journal of Psychopharmacology, 28(3), 179-203. doi: 10.1177/0269881113519509

CADDRA. (2011). Canadian ADHD practice guidelines. Toronto: Canadian Attention Deficit Hyperactivity Disorder Resource Alliance.

COFEPRIS. (2015). Comunicado de Prensa 07/15. Retrieved from: http://www.cofepris.gob.mx/Documents/NotasPrincipales/25012015.pdf

Coghill, D., Banaschewski, T., Lecendreux, M., Soutullo, C., Johnson, M., Zuddas, A., ... Squires, L. (2013). European, randomized, phase 3 study of lisdexamfetamine dimesylate in children and adolescents with attention-deficit/hyperactivity disorder. European Neuropsychopharmacology, 23(10), 1208-1218. doi: 10.1016/j.euroneuro.2012.11.012

Coghill, D. R., Caballero, B., Sorooshian, S., \& Civil, R. (2014). A Systematic Review of the Safety of Lisdexamfetamine Dimesylate. CNS Drugs, 28(6), $497-$ 511. doi: 10.1007/s40263-014-0166-2

Diaz-Orueta, U., Fernandez-Fernandez, M. A., Morillo-Rojas, M. D., \& Climent, G. (2016). Efficacy of lisdexamphetamine to improve the behavioural and cognitive symptoms of attention deficit hyperactivity disorder: treatment monitored by means of the AULA Nesplora virtual reality test. Revista de neurologia, 63(1), 19-27.

Ermer, J. C., Pennick, M., \& Frick, G. (2016). Lisdexamfetamine Dimesylate: Prodrug Delivery, Amphetamine Exposure and Duration of Efficacy. Clinical Drug Investigation, 36(5), 341-356. doi: 10.1007/s40261-015-0354-y

Faraone, S. V. \& Buitelaar, J. (2010). Comparing the efficacy of stimulants for ADHD in children and adolescents using meta-analysis. European Child \& Adolescent Psychiatry, 19(4), 353-364. doi: 10.1007/s00787-009-0054-3

Faraone, S. V, Sergeant, J., Gillberg, C., \& Biederman, J. (2003). The worldwide prevalence of ADHD: is it an American condition? World psychiatry, 2(2), 104-113.

Findling, R. L., Childress, A. C., Cutler, A. J., Gasior, M., Hamdani, M., Ferreira-Cornwell, M. C., \& Squires, L. (2011). Efficacy and Safety of Lisdexamfetamine Dimesylate in Adolescents With Attention-Deficit/Hyperactivity Disorder. Journal of the American Academy of Child \& Adolescent Psychiatry, 50(4), 395-405. doi: 10.1016/j.jaac.2011.01.007

Findling, R. L., Cutler, A. J., Saylor, K., Gasior, M., Hamdani, M., Ferreira-Cornwell, M. C., \& Childress, A. C. (2013). A Long-Term Open-Label Safety and Effectiveness Trial of Lisdexamfetamine Dimesylate in Adolescents With Attention-Deficit/Hyperactivity Disorder. Journal of Child and Adolescent Psychopharmacology, 23(1), 11-21. doi: 10.1089/cap.2011.0088 
Gonzalez-Covarrubias, V., Martínez-Magaña, J. J., Coronado-Sosa, R., Villegas-Torres, B., Genis-Mendoza, A. D., Canales-Herrerias, P., ... \& Soberón, X. (2016). Exploring Variation in Known Pharmacogenetic Variants and its Association with Drug Response in Different Mexican Populations. Pharmaceutical Research, 33(11), 2644-2652. doi: 10.1007/s11095-016-1990-5

Goodman, D., Faraone, S. V, Adler, L. A., Dirks, B., Hamdani, M., \& Weisler, R. (2010). Interpreting ADHD rating scale scores: linking ADHD rating scale scores and CGI levels in two randomized controlled trials of lisdexamfetamine dimesylate in ADHD. Primary Psychiatry, 17(3), 44.

Hodgkins, P., Shaw, M., Caci, H., Young, S., Kahle, J., Woods, A. G., \& Arnold, L. E. (2012). A systematic review and analysis of long-term outcomes in attention deficit hyperactivity disorder: Effects of treatment and non-treatment. BMC Medicine, 10(1), 99. doi: 10.1186/1741-7015-10-99

Li, Y., Gao, J., He, S., Zhang, Y., \& Wang, Q. (2017). An Evaluation on the Efficacy and Safety of Treatments for Attention Deficit Hyperactivity Disorder in Children and Adolescents: a Comparison of Multiple Treatments. Molecular Neurobiology, 54(9), 6655-6669. doi: 10.1007/s12035-016-0179-6

Lopez, C. A. (2014). Manual diagnóstico y estadístico de los trastornos mentales: DSM-5. Editorial Médica Panamericana.

National Institute for Health and Care Excellence. (2018). Attention deficit hyperactivity disorder: diagnosis and management. Guidance and guidelines NICE. Retrieved from https://www.nice.org.uk/guidance/NG87

de la Peña, F., Barragán Pérez, E., Rohde, L. A., Durán, L. R. P., Ramírez, P. Z., Flores, R. E. U., ... Larraguibel, M. (2009). Algoritmo de tratamiento multimodal para escolares latinoamericanos con trastorno por déficit de atención con hiperactividad (TDAH). Salud Mental, 32(S1), 17-29.

Pérez, E. B. (2010). Las enfermedades neuropsiquiátricas en Latinoamérica y sus retos. Consejo Editorial 2009-2010, 78(4), 173.

Polanczyk, G., de Lima, M. S., Horta, B. L., Biederman, J., \& Rohde, L. A. (2007). The Worldwide Prevalence of ADHD: A Systematic Review and Metaregression Analysis. American Journal of Psychiatry, 164(6), 942-948. doi: 10.1176/ ajp.2007.164.6.942
Polanczyk, G. V, Willcutt, E. G., Salum, G. A., Kieling, C., \& Rohde, L. A. (2014) ADHD prevalence estimates across three decades: an updated systematic review and meta-regression analysis. International Journal of Epidemiology, 43(2), 434-442. doi: 10.1093/ije/dyt261

Punja, S., Schmid, C. H., Hartling, L., Urichuk, L., Nikles, C. J., \& Vohra, S. (2016). To meta-analyze or not to meta-analyze? A combined meta-analysis of N-of-1 trial data with RCT data on amphetamines and methylphenidate for pediatric ADHD. Journal of Clinical Epidemiology, 76, 76-81. doi: 10.1016/j.jclinepi.2016.03.021

Punja, S., Shamseer, L., Hartling, L., Urichuk, L., Vandermeer, B., Nikles, J., \& Vohra, S. (2016). Amphetamines for attention deficit hyperactivity disorder (ADHD) in children and adolescents. Cochrane Database of Systematic Reviews. doi: 10.1002/14651858.CD009996.pub2

Riera, M., Castells, X., Tobias, A., Cunill, R., Blanco, L., \& Capellà, D. (2017). Discontinuation of pharmacological treatment of children and adolescents with attention deficit hyperactivity disorder: meta-analysis of 63 studies enrolling 11,788 patients. Psychopharmacology, 234(17), 2657-2671. doi: 10.1007/ s00213-017-4662-1

Sosa-Macías, M., Teran, E., Waters, W., Fors, M. M., Altamirano, C., Jung-Cook, H., ... \& Hernández, F. (2016). Pharmacogenetics and ethnicity: relevance for clinical implementation, clinical trials, pharmacovigilance and drug regulation in Latin America. Pharmacogenomics, 17(16), 1741-1747. doi: 10.2217/pgs2016-0153

Stuhec, M., Munda, B., Svab, V., \& Locatelli, I. (2015). Comparative efficacy and acceptability of atomoxetine, lisdexamfetamine, bupropion and methylphenidate in treatment of attention deficit hyperactivity disorder in children and adolescents: A meta-analysis with focus on bupropion. Journal of Affective Disorders, 178, 149-159. doi: 10.1016/j.jad.2015.03.006

Wang, L. J., Yang, K. C., Lee, S. Y., Yang, C. J., Huang, T. S., Lee, T. L., ... Shyu, Y. C. (2016). Initiation and Persistence of Pharmacotherapy for Youths with Attention Deficit Hyperactivity Disorder in Taiwan. PLoS ONE, 11(8), e0161061. doi: 10.1371/journal.pone.0161061 